ISSN 0001-6002/2003/45/4/158-164

Acta Médica Costarricense,(@2003

Colegio de Médicos y Cirujanos

\title{
Floraciones algales nocivas en la costa pacífica de Costa Rica: Toxicología y sus efectos en el ecosistema y salud pública.
}

\author{
Enrique Freer, Maribel Vargas-Montero.
}

Justificación y objetivos: Los primeros casos de intoxicación por floraciones algales nocivas (FAN) se reportaron en el país en 1990. Sin embargo desde finales de 1999 se ha observado un aumento drástico en el número de personas intoxicadas, especialmente en la costa pacífica del país. En Costa Rica existe gran desconocimiento acerca del problema. Debido al impacto que producen los fenómenos FAN en la salud pública, el turismo local y el ecosistema, es necesario describir las especies tóxicas y sus toxinas para tomar las medidas adecuadas de control y prevención.

Métodos: Se realizaron muestreos de agua en varios sectores de la costa pacífica de nuestro país, con el objetivo de detectar las especies de microalgas potencialmente tóxicas y nocivas, y se interrogó a los pescadores locales. La identificación de las especies se realizó morfológicamente mediante microscopía de luz y electrónica de rastreo. Los hallazgos se compararon con la bibliografía y se propuso el potencial tóxico de estas microalgas, así como los métodos de análisis toxicológico, y la sintomatología de los afectados.

Resultados: Observamos en Costa Rica un aumento en número de especies de microalgas productoras de FAN. Se reportaron las especies tóxicas productoras de FAN descritas por varios autores y las encontradas en este estudio. En algunas muestras de floraciones algales hemos encontrado bacterias grandes intracelulares, de forma bacilar, principalmente dentro del dinoflagelado Prorocentrum micans. Esta relación podría estar asociada a la toxigenicidad del alga. Hemos descrito la presencia de 26 dinoflagelados, 8 diatomeas y 1 cianobacteria tóxica en las FAN de las costas del Océano Pacífico costarricense.

Conclusión: Se piensa que el aumento en la contaminación de las zonas costeras y el transporte de especies por medio de navíos pueden ser la causa de la aparición de estas microalgas. Estas son capaces de producir: intoxicación paralizante, amnésica, diarréica, neurotóxica, ciguatera y fiebre de Tamandré. Es importante que el personal de salud tenga un buen conocimiento de las FAN y se necesita con urgencia un adecuado programa de monitoreo y control en Costa Rica, para proteger a la población.

Descriptores: mareas rojas, floraciones algales nocivas, dinoflagelados, toxicología.

Recibido: 10 de abril de 2003

Aceptado: 23 de setiembre de 2003

\footnotetext{
Abreviaturas: AO, ácido okadaico; BR, bioensayo en ratón; FAN, floraciones algales nocivas; CLAP, cromatografía líquida de alta presión; IAM, intoxicación amnésica por marisos; IDM, intoxicación diarréica por mariscos; IPM, intoxicación paralizante por mariscos; MAG-S, ministerio de agricultura y ganadería laboratorio de sanidad; $\mathrm{MEB}$, microscopio electrónico de barrido; UR, unidades ratón; VCP, veneno ciguatérico de pescado.

${ }^{1}$ Centro de Investigación en Estructuras Microscópicas, CIEMic, Universidad de Costa Rica.

Correspondencia: CIEMic, Ciudad de la Investigación, Universidad de Costa Rica, CP2060, Costa Rica. Fax: 2073182.

E-mail: efreer@cariari.ucr.ac.cr
}

El término FAN (floraciones algales nocivas) lo designó la Comisión Oceanográfica Intergubernamental de la $\mathrm{UNESCO}^{1}$, y se usa para designar microalgas, bacterias y ciliados que pueden producir daños al hombre por sus efectos adversos en la salud humana, en la acuicultura, turismo y en las poblaciones naturales de organismos marinos en las zonas costeras $^{2}$. El aumento en la concentración de microalgas pigmentadas en el mar, produce discoloraciones en el agua, debido a que pueden alcanzar concentraciones muy elevadas, en el orden de los $10^{6} \mathrm{cel} \mathrm{x} \mathrm{L}^{-1} \quad{ }^{2}$ Figuras. 1A y 2E. Muchas de estas microalgas son parte del fitoplancton que engloba diversas especies de tamaño microscópico, con escasa capacidad de movimiento y que, por lo tanto, son transportadas pasivamente por la masa de agua en donde viven. 
El fitoplancton tiene una especial relevancia para las especies marinas, porque constituye el nivel trófico primario en los ecosistemas acuáticos, es la fuente fundamental de alimento para los organismos filtradores (mejillón, almeja, piangua, etc.) y algunas especies tienen efectos nocivos para los bivalvos y peces, lo que frena su desarrollo y las hacen tóxicas para el consumo humano.

Se cree que el registro más antiguo que se tiene sobre una floración algal o marea roja, se cita en la Biblia: “...y las aguas del Nilo se convirtieron en sangre. Los peces del Nilo murieron, el río empezó a oler mal y los egipcios no podían beber de sus aguas. Todo Egipto se lleno de sangre." (Exodo 7: 202, Santa Biblia). El primer informe de muertes por intoxicación paralizante (IPM) por consumo de mariscos se produjo en 1793, en la tripulación del barco Capitán George Vancouver, en la Columbia Británica ${ }^{1}$, y el primer caso de intoxicación amnésica (IAM) por ingestión de mariscos contaminados se documentó en la Isla Príncipe Eduardo (Canadá) en 1987, cuando más de 100 personas enfermaron y muchas murieron por la ingestión de moluscos bivalvos contaminados. Las floraciones algales en Costa Rica son fenómenos que van en aumento en los últimos años, en especial en la costa Pacífica del país ${ }^{3}$. Existe poco conocimiento, debido a la ausencia de registros de mareas rojas (principalmente tóxicas) y escasos estudios sobre el tema. Además, la falta de laboratorios costeros bien equipados, el difícil acceso a las zonas de muestreo, la carencia de personal regional capacitado, la ausencia de datos epidemiológicos y toxicológicos, y la inexistencia de una política adecuada impiden el desarrollo de un programa de monitoreo. El gobierno, al no estar preparado económicamente para solventar problemas de esta envergadura, decretó un periodo prolongado de veda y se complementó con el subsidio de más de 300 millones de colones a más de 600 familias de pescadores artesanales del área Pacífica.

Debido al gran impacto ambiental, económico, social y de la salud pública es necesario contribuir en alguna medida con un programa de monitoreo de mareas rojas, para definir los agentes causales y los factores que las producen, como son: la cantidad de luz, salinidad, turbulencia, temperatura y macronutrientes ${ }^{4}$. Cuando se conozca las especies tóxicas en Costa Rica y la bioquímica y fisiopatología de las toxinas, se podrá realizar un diagnóstico preciso y rápido para ofrecer un mejor tratamiento en los casos que lo ameriten. El objetivo de este trabajo es describir las principales especies de organismos que forman parte del fitoplancton marino y son productoras de mareas rojas en Costa Rica, así como describir sus toxinas, la fisiopatología, clínica y tratamiento, con el fin de aumentar la información del personal responsable de ofrecer los servicios de salud en las zonas afectadas.

\section{Materiales y métodos}

Desde 1997, el Centro de Investigación en Estructuras Microscópicas colectó muestras de agua, tanto en superficie como a 5 metros de profundidad, en diversos sectores de la costa pacífica. Las colectas se realizaron en un promedio cada
22 días, en la parte interna del Golfo de Nicoya, Puntarenas, estero de Puntarenas, Paquera, Puerto Caldera y Quepos. Se anotaron las observaciones de los pescadores y sus familiares acerca de los padecimientos asociados con las FAN. La muestras se colectaron con botella Niskin de 1 litro de capacidad, con el propósito de realizar conteos celulares y mediante una colecta en la superficie con una red para fitoplancton de $20 \mu \mathrm{m}$ de grosor de poro. Las muestras se fijaron en solución de Karnovsky amortiguada en cacodilato de sodio al $0.1 \mathrm{M}, \mathrm{pH} 7.4^{5}$. El procesamiento se realizó para microscopía electrónica de barrido (MEB) y para microscopía de luz. Para $\mathrm{MEB}$, las muestras fueron posfijadas con tetraóxido de osmio al $1 \%$, durante $1 \mathrm{~h}$. Se deshidrataron mediante un gradiente ascendente de alcohol etílico y se infiltraron en acetato de amilo para su posterior secado en punto crítico. Luego se montaron sobre bases de aluminio y se recubrieron con una capa de platino de $30 \mathrm{~nm}$ de grosor, en un cobertor iónico marca Hitachi, modelo IB-5. La muestras se observaron con un microscopio electrónico de barrido Hitachi S-2360N, a un voltaje de aceleración de $15 \mathrm{KV}$. Las microalgas encontradas fueron fotografiadas y caracterizadas morfológicamente, para identificarlas taxonomicamente. Con el microscopio óptico se observaron las microalgas vivas y se determinó el lugar de algunas organelas importantes para su clasificación. Se prepararon láminas fijas en resina para ser fotografiadas y en algunos casos se agregó hipoclorito de sodio, con el fin de despegar las placas de dinoflagelados armados para identificar al microorganismo. Los dinoflagelados se mantuvieron en cultivos unialgales para enviar muestras a laboratorios especializados y determinar la presencia de toxinas ellas. Con el propósito de identificar y reportar las especies, las micrografías electrónicas se compararon con la información existente en bases de datos internacionales y con la ayuda de expertos extranjeros.

\section{Resultados y discusión}

En el Cuadro No. 1 se presentan las microalgas y ciliados marinos potencialmente dañinos de la costa Pacífica de Costa Rica. En el primer informe de FAN en Costa Rica, en 1981, se identificó al dinoflagelado Gymnodinium catenatum ${ }^{6}$, luego, en 1985, se describió una FAN ocasionada por Gonyaulax digitale $^{7}$. En 1990 se reportó el primer caso conocido en Costa Rica de (IPM) por consumo de Mariscos, que afectó a un grupo de personas en la costa Pacífica, siendo el dinoflagelado tóxico productor de la floración P. bahamense var. compressum y el principal vector el molusco ostión vaca (Spondylus calcifer $)^{8}$. Estas floraciones de microorganismos, además de reducir el oxígeno disuelto en el agua, tienen un gran impacto ecológico en muchas regiones del mundo y causan mortalidad de otros organismos acuáticos, incluyendo corales y peces ${ }^{9,10}$. Se ha encontrado una alta mortalidad de corales en las costas pacíficas de Costa Rica, producida especialmente por una floración dominada por los dinoflagelados Cochlodinium catenatum y Gonyaulax monilata (ahora Alexandrium monilatum) ${ }^{11}$. En 1995 se identificó a los dinoflagelados Prorocentrum balticum, Gymnodinium catenatum y Alexandrium monilatum, 
como productores de floraciones algales en la costa Pacífica de nuestro país ${ }^{13}$. A finales de 1999 se detectó una FAN frente a las costas de Puntarenas, Pacífico Central, que perduró hasta marzo de 2002, desapareciendo y reapareciendo intermitentemente durante ese periodo, y cuya extensión abarcó desde la parte norte en Guanacaste, hasta el sur de la costa Pacífica en Quepos, incluyendo el Golfo Dulce ${ }^{13}$. En esta oportunidad los dinoflagelados que se encontraron en la floración fueron Pyrodinium bahamense var. bahamense y var. compressum, además de Gymnodinium catenatum. (Figuras. 1B y C). En 2001 se reportó una floración algal de Lingulodinium polyedrum en Bahía Culebra, Pacífico Norte ${ }^{14}$. Aeste dinoflagelado se le ha relacionado con la producción de yesotoxinas. En $2002{ }^{15}$ se informó el primer caso de FAN dominadas por diatomeas en Costa Rica, especificamente la diatomea que dominaba la floración fue Pseudo-Nitzschia pungens (Figuras. 1D y E), la cual ha sido relacionada con producción de ácido domóico, y en menores concentraciones se encontraban las diatomeas Skeletonema costatum, Chaetoceros lorenzianus, las cuales han estado vinculadas con el daño a las branquias

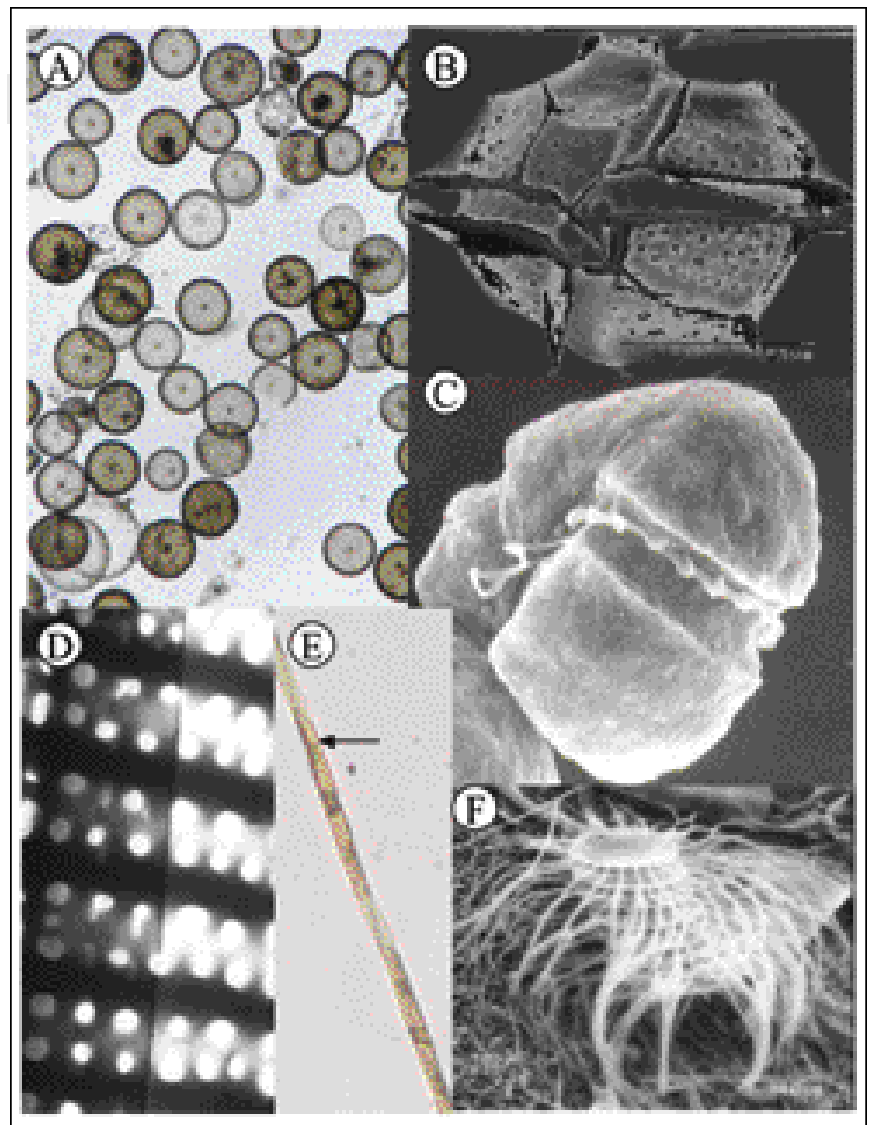

Figura 1 A. FAN producida por diatomeas del género Coscinodiscus sp. B.Micrografía electrónica de barrido (MEB) del dinoflagelado tóxico Pyrodinium bahamense, C.MEB. Dinoflagelado tóxico Gymnodinium catenatum, D. Micrografía electrónica de transmisión (MET) de la diatomea tóxica Pseudo-Nitzschia pungens, E. Diatomea Pseudo-Nitzschia pungens vista con un microscopio de luz (flecha:detalle que se observa aumentado 4.000X en la figura D). F. MEB. Diatomea Bacteriastrum cf. hyalium, con sus extensas setas que dificultan la respiración de los peces. de los peces, por sus resaltadas estructuras silíceas (Figuras1F y 2 A y B).

En mayo de 2002, se reportaron 17 casos de intoxicación, principalmente en niños de la localidad de Caldera ${ }^{16}$. Los afectados manifestaron dolor abdominal, trastornos respiratorios y ardor en los ojos; además, aparecieron cientos de peces muertos en la playa. Las microalgas que dominaban la floración fueron el dinoflagelado Cochlodinium cf. polykrykoides y la cianobacteria Trichodesmiun erythraeum (Figuras. 2D y E), la cual ha sido asociada con el síndrome conocido como "febre de Tamandaré" o "tingui”, denominado así por el nombre de una localidad en la costa noreste de Brasil. Este provoca dermatitis por contacto de tipo químico y es la causa de grandes molestias en las poblaciones donde se han encontrado FAN². Según algunos pescadores entrevistados en la zona de Punta Cuchilla (Paquera) y Puntarenas, al momento de lavar sus redes de pesca y tener contacto con el agua de mar contaminada con la marea roja, presentaron dermatitis generalizada en algunos casos. Los pescadores entrevistados que sufrieron una intoxicación paralizante, recuerdan haberse sentido mal a los 30 min de haber ingerido los ostiones contaminados, refiriendo parestesias en la lengua, cefalea,

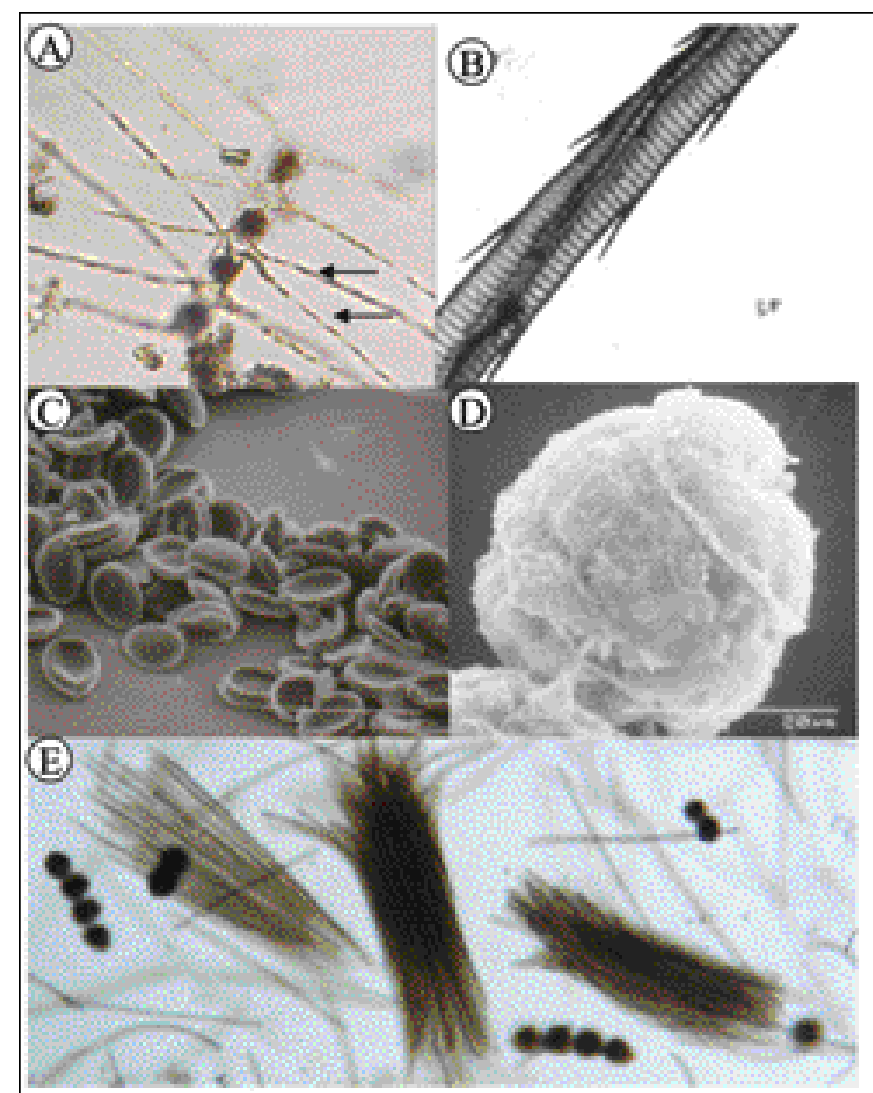

Figura 2.A.Luz.Diatomea Chaetoceros cf. borealis (flechas:señalan el detalle de las setas que se observa en la figura B), B. MET. Detalle de las setas de Chaetoceros cf. borealis aumentada 5.000X, C. MEB. Floración del dinoflagelado tóxico Prorocentrum minimum, D. MEB.Célula del dinoflagelado Cochlodinium cf. polykrikoides. E. FAN producida por filamentos de la cianobacteria Trichodesmium erytraeum. 
naúseas, disartria y disnea. Uno de los intoxicados refiere haber estado hospitalizado durante tres meses debido a una parálisis generalizada. Recientemente se encontró altas concentraciones del dinoflagelado tóxico Prorocentrum minimum (Figura 2C) frente a la costa de Puntarenas, especie que en el pasado no había sido observada.

\section{Intoxicaciones producidas por FAN}

Intoxicación Paralizante por Moluscos (IPM): Este tipo de intoxicación constituye la principal amenaza para la salud pública en América Latina ${ }^{1,2}$. Las toxinas que conforman la IPM están formadas por un núcleo tetrahidropurínico, siendo todas ellas análogas a la saxitoxina. Actualmente existen más de 26 derivados de la saxitoxina ${ }^{17,18}$. Desde el punto de vista técnico, la cuantificación de las toxinas de este grupo es muy difícil, debido a su complejidad y gran número de derivados químicos. Este grupo de toxinas se distribuye en el Pacífico Sudamericano y en el Atlántico ${ }^{2,19}$ y es el tipo de intoxicación que se ha presentado en la costa Pacífica costarricense desde hace más de 20 años ${ }^{3,16,8}$. Las personas que ingieren moluscos bivalvos contaminados con toxinas de marea roja, presentan cuadros neurotóxicos en los primeros $15 \mathrm{~min}$. de haber ingerido la toxina, pues esta se absorbe en la mucosa bucal y gástrica. El grado de intoxicación varía dependiendo de la cantidad de toxina ingerida. Las primeras manifestaciones son: parestesia bucal o sensación de hormigueo alrededor de la boca, que se trasmite luego a manos y pies. Luego aparecen la cefalea y náuseas, seguida por incoordinación al hablar, alteración del pulso y dificultad respiratoria. En casos graves ocurre una parálisis muscular flácida, insuficiencia respiratoria y posterior paro cardiorrespiratorio ${ }^{2,17,18}$. Las toxinas paralizantes alteran el transporte del ion sodio y son capaces de unirse con alta afinidad a su receptor en la membrana, que es el canal de sodio presente en células de mamíferos, aves, peces y anfibios, y también en invertebrados como los moluscos bivalvos ${ }^{19}, 20$. Estas toxinas se dividen en las bloqueadoras del canal de sodio, entre las que se encuentran las saxitoxinas, tetrodotoxina y toxinas de caracoles marinos; y en las activadoras del canal de sodio, siendo estas las ciguatoxinas, brevetoxinas Ay B ${ }^{19}$. El número de moléculas de toxina capaces de unirse al canal de sodio es muy alto bloqueo del paso de iones sodio hacia el interior de la célula, lo que causa parálisis neuromuscular ${ }^{21}$ y paro respiratorio en mamíferos ${ }^{2}$. Debido a las características estructurales de estas toxinas, presentan diferencias en la potencia tóxica, la cual, por conveniencia, se expresa en Unidades Ratón (UR) por mmol de toxina. Así se puede calcular la toxicidad de las muestras de moluscos sospechosos y expresarla en unidades equivalentes (Unión Europea Norma ISO/CEI 17025 en 1999, ley 91/492/EEC de la Comunidad Económica Europea).

Las toxinas bloqueadoras inhiben los potenciales de acción, interfiriendo en las funciones de la actividad nerviosa, produciendo la muerte por parálisis flácida ${ }^{2,17,18,19}$. Las toxinas activadoras no son letales, pero pueden afectar gravemente al paciente induciendo problemas gástricos severos, parestesias, y alteraciones del equilibrio. Si el paciente presenta disnea debe hospitalizarse, realizar lavado gástrico o provocar el vómito y de inmediato se le administran medicamentos que retarden la absorción de las toxinas, como suspensiones antiácidas basadas en hidróxido de aluminio o magnesio, además de bloqueadores de la secreción gástrica y carbón activado. No existe un antídoto conocido para estas toxinas y el tratamiento está limitado a respiración asistida ${ }^{17,20}$.

Intoxicación Diarréica por Moluscos (IDM): Las toxinas del tipo diarréico son moléculas polietéreas lipofílicas ${ }^{22}$, como el ácido okadaico (AO), pectenotoxinas, yesotoxinas dinofisitoxina 1 (DTX1), dinofisistoxina 2 (DTX2) y las dinofisistoxina 3 (DTX3) $)^{2,23}$ y sus derivados dinophysistoxina 1 y 2 (DTX-1, DTX-2) y otros compuestos como odularinas y caniculina $\mathrm{A}^{19}$. Tienen alto peso molecular y son liposolubles ${ }^{24}$. El mecanismo de acción es mediante la inhibición de las fosfatasas, o sea, de las enzimas que disminuyen el grado de fosforilación de proteínas que controlan la permeabilidad del epitelio intestinal. Los pacientes afectados por estas toxinas presentan náuseas, vómito, dolor abdominal y una diarrea secretoria que los lleva a la deshidratación. Este tipo de intoxicación diarréica que se produce por el consumo de mariscos contaminados, es similar al ocasionado por el cólera, por lo que, para realizar el diagnóstico diferencial, se debe investigar el tipo de alimentos ingeridos recientemente y efectuar un análisis de toxina a los moluscos, con el fin de confirmar la presencia del ácido okadaico. El tratamiento consiste en corregir el desequilibrio hidroelectrolítico. Los síntomas pueden durar 4 días, por lo que se debe evitar la muerte por deshidratación.

Intoxicación neurotóxica por moluscos (INM): Este tipo de intoxicaciones son producidas por un grupo de dinoflagelados del género Gymnodinium, el cual se denominaba Gymnodinium brevis, ahora conocido como Karenia brevis. Se conocen 8 tipos diferentes de toxinas denominadas brevetoxinas. Estas provocan muertes masivas de peces y mamíferos marinos, mediante un mecanismo de acción todavía desconocido. En humanos, actúan en las neuronas bloqueando los canales de sodio y despolarizando la musculatura lisa del tejido bronquial ${ }^{17}$. La intoxicación puede ocurrir por contacto directo con la brisa marina o por la ingesta de moluscos bivalvos o peces contaminados. Los síntomas producidos por las brevetoxinas son similares a los producidos por la ciguatera, pero sin los efectos de la larga duración de la sintomatología. Incluyen náuseas, vómito, diarrea, escalofríos, mareos, parestesias en la cara, manos y pies, y esto ocurre de 3 a 4 horas después de la ingestión del marisco ${ }^{17}$. Este tipo de intoxicación no requiere tratamiento especializado. El método de detección de las toxinas tipo NSP, aceptado en los Estados Unidos por la A m e r i c a n Public Health Association, es el bioensayo en ratón, el cual se basa en la aplicación intraperitoneal de $1 \mathrm{ml}$ de extracto acidificado de molusco a un ratón y el registro de tiempo de muerte del organismo, que convierte las unidades ratón a concentraciónes de PSP, al estandarizar del método por el uso de una solución de referencia de saxitoxina ${ }^{25}$. 
Intoxicación amnésica por moluscos (IAM): Las toxinas que producen la intoxicación amnésica son toxinas aminodicarboxílicas, conocidas como toxinas del ácido domóico ${ }^{18}$. El ácido domóico es un aminoácido soluble en agua y contiene tres residuos ácido carboxílicos que unen metales ${ }^{26}$. El ácido domóico produce una respuesta 100 veces más potente que el ácido glutámico ${ }^{2}$, que un neurotransmisor natural del sistema nervioso central y tiene la propiedad de unirse con alta afinidad a receptores de glutamato presentes en altas concentraciones en las neuronas del hipocampo, siendo las responsables del procesamiento de la memoria ${ }^{19}$. La intoxicación por toxinas amnésicas produce la entrada de calcio a las neuronas del hipocampo y, eventualmente causa su destrucción y la pérdida de memoria de corta duración y una neurodegeneración irreversible. Este tipo de intoxicaciones, además de alterar en los procesos de memoria y orientación, produce trastornos como náuseas, vómito, diarrea, cólicos abdominales, dolor de cabeza, secreción bronquial, dificultad respiratoria y pérdida del equilibrio ${ }^{17,18}$. La conducta a seguir es hacer un análisis químico del alimento ingerido en las últimas 24 h, para detectar el ácido domóico presente y dar tratamiento sintomático, ya que no existe uno específico ${ }^{17}$.

Ciguatera o veneno ciguatérico de pescado (VCP): La ciguatera es un síndrome causado por el consumo de peces tropicales y subtropicales contaminados principalmente con ciguatoxinas. Produce desórdenes gastrointestinales, cardiovasculares y, a las pocas horas, el desarrollo de síntomas neurológicos, entre los que se encuentra la reversión de sensación de temperatura. La desintoxicación es lenta, ya que se han reportado casos en los cuales los síntomas perduran durante toda la vida del paciente. Ha producido muertes humanas en el Océano Índico, sin embargo, son raros los informes de muertes en el Océano Pacífico y el Caribe ${ }^{17}$. Las ciguatoxinas son un grupo de poliéteres de bajo peso molecular, liposolubles, estables al calor y activadores del canal de sodio ${ }^{17}$. El bioensayo en ratón es el método de detección más utilizado para las ciguatoxinas en peces y ensayos in vivo utilizando camarones, larvas de dípteros, gatos, pollos y mosquitos, ya que el bioensayo en ratón no estandariza todos los diferentes tipos de ciguatoxinas. Estos procedimientos requieren de un tiempo de observación largo en los ratones, además, para la confirmación de las toxinas se precisan de métodos analíticos, como espectroscopia de masas o cromatografía líquida de alta resolución (CLAP) ${ }^{2,17}$.

Toxinas de acción rápida: Las toxinas de acción rápida son un nuevo grupo de toxinas que inducen síntomas neurotóxicos y la muerte rápida por un mecanismo de acción aún desconocido ${ }^{27}$. Entre este grupo de toxinas están los espirolidos del A al D, las pinnatoxinas y las gymnodininas ${ }^{17}$. Los espirolidos son toxinas emergentes en el plancton y moluscos, compuestos macrocíclicos biológicamente activos, consistiendo en un sistema tricíclico espiroligado de un anillo éter ${ }^{28}$, que procede de los dinoflagelados marinos Alexandrium ostenfeldii, A. tamarense, Fragilidium subglobosum, Gonyaulax spinifera, Gonyaulax grindleyi (antes Protoceratium reticulatum), y Scrippsiella trochoidea, especies que se encuentran en el Pacífico de Costa Rica ${ }^{29}$. Los azaspirácidos pertenecen a este nuevo grupo de ficotoxinas encontradas como responsables de una intoxicación similar a la intoxicación IDM, asociada al consumo del moluscos bivalvos en cultivo, como Mytilus edulis y Crassostrea gigas, en Europa e Irlanda ${ }^{17,30,31}$. Se ha detectado el Protoperidinium crassipes, como el dinoflagelado fuente de azaspirados ${ }^{17}$. Este dinoflagelado está presente en el Golfo de Nicoya ${ }^{29,32}$. Los azaspirácidos son persistentes en mariscos y se han encontrado en mejillones hasta 8 meses después de la intoxicación inicial ${ }^{30}$. Los síntomas son similares a los de la IDM, sin embargo, constituyen un nuevo síndrome que ha sido llamado intoxicación por azaspirácidos (IA).

No se conoce con exactitud por qué los dinoflagelados producen toxinas que afectan al hombre. Se cree que existen varios factores ligados a estos, como son la producción de metabolitos secundarios, la simbiosis con bacterias, la ventaja selectiva que tienen estas especies, las reservas de nitrógeno, la producción de bioluminiscencia, expresión de mecanismos de defensa, o bien, como competencia con otras especies fitoplanctónicas ${ }^{1}$. En muestras de floraciones algales en Costa Rica, hemos encontrado bacterias grandes intracelulares, de forma bacilar, principalmente dentro del dinoflagelado Prorocentrum micans. Esta relación podría asociarse a la toxigenicidad del alga ${ }^{29}$. En otros estudios ${ }^{33,34}$ se han observado bacterias productoras de toxinas asociadas simbióticamente con dinoflagelados y se menciona que su toxigenicidad puede influenciar los focos de toxicidad algal por los niveles de asociación entre la bacteria y el alga. Recientes estudios han demostrado que las bacterias desempeñan una función muy importante en el control de las floraciones algales, regulando el impacto y la toxicidad producida por estas ${ }^{35}$.

Actualmente ocurren cambios climáticos globales, algunos de ellos por la actividad humana. Por ejemplo, el aumento de la radiación ultravioleta modifica la composición de las comunidades de fitoplancton en los sistemas costeros y aumenta las FAN. Los grandes navíos del transporte marítimo internacional utilizan agua como lastre para estabilización; la succionan en grandes cantidades en diversas regiones y luego la descargan en nuestras costas. De esta manera diseminan las células vegetativas y las esporas de especies tóxicas pasan a formar parte de los sedimentos marinos en un nuevo hábitat, constituyen parte de la flora tóxica endémica en la zona ${ }^{1}$.

Los países con experiencia y recursos para afrontar las FAN tienen rigurosos planes de manejo y monitoreo de las floraciones algales para la vigilancia de la salud ${ }^{2,17}$. En Costa Rica este tipo de programas apenas comienzan a desarrollarse ${ }^{36}$. El 6 de marzo de $2001{ }^{37}$ se instituyó el decreto No. 20359 MAG-S, que crea la Comisión Interinstitucional para el Control de la Marea Roja en Costa Rica, como órgano asesor y consultivo, adscrito al MAG con el objetivo de detectar la presencia de microorganismos y sus toxinas. Periódicamente se monitorean las costas para identificar áreas de riesgo y determinar la magnitud de su extensión, con el fin de hacer una declaratoria oportuna de veda para la extracción, expendio y consumo de moluscos. Sin embargo, la falta de recursos hace que este tipo de iniciativas no funcione adecuadamente. Mientras tanto, el peligro potencial de intoxicaciones masivas por toxinas presentes en moluscos es muy alto, y nuestra población o los turistas no cuentan con información suficiente. Por otro lado, el personal responsable de los servicios de 
salud no está adecuadamente educado en el diagnóstico y manejo de este tipo de intoxicaciones.

\section{Agradecimientos}

Los autores agradecen la colaboración de la Vicerrectoría de Investigación de la Universidad de Costa Rica; a la Dra. Beatriz Reguera, del Instituto Español de Oceanografía por sus comentarios y su colaboración con la identificación taxonómica de algunas especies como Cochlodinium cf. polykrikoides y Prorocentrum minimun; al personal del CIEMic, y a los pescadores de Puntarenas por sus valiosas observaciones y asistencia en la colecta las muestras. También se gradece el apoyo económico del CONICIT-MICIT, para la presentación de estos datos en congresos internacionales.

\section{Abstract}

Justification and Objectives: The first cases of intoxication due to Harmful Algae Blooms (HAB) in Costa Rica were reported in 1990. However, towards the end of 1999 a drastic increase of poisoned people was observed, especially along our pacific coast. There is lack of information regarding the problems of HAB. Due to the impact of HAB on public health, local tourism and the ecosystem, it is necessary to describe toxic species and their toxins in order to apply adequate control and preventive measures.

Methods: Water samples were taken in various locations along the costarican pacific coast with the aim of detecting potentially toxic and harmful species of microalgae. Species identification was carried out morphologically by means of light and scanning electron microscopy. These findings were compared with current literature and the potential toxin of these microalgae was proposed as well as the methods of toxicological analysis and the clinical findings of those aff e c te d .

Results: Recently, an increase in the number of HAB producing microalgae species has been observed in Costa Rica. This study reports these findings together with ones from those of other authors related to HAB producing species in Costa Rica. In few algal bloom samples, large intracellular bacillary bacteria were found, mainly within the dinoflagellate Prorocentrum micans. This relation may be associated with the toxicity of the algae.

Discussion: It is believed that the increase in coastal zone pollution and the transportation of species by means of ships ballast water may be the cause of the appearance of these microalgaes. The presence of 26 dinoflagellates, 8 diatoms and 1 cyanobacteria, all potentially harmful in HAB events, was currently demonstrated along the pacific coast of Costa Rica. These microalgae are capable of producing toxins which may cause: paralysis, amnesia, diarrheia, and neurotoxicity poisonings, ciguatera and Tamandré fever. It is important that health personnel be knowledgeable regarding HAB events and to implement an effective monitoring and program control in Costa Rica in order to protect the population.

\section{Referencias}

1. Hallegraeff G.M., Anderson D.M., Cembella A.D. Manual of Harmful Marine Microalgae. Intergovernmental Oceanographic Commission (UNESCO). 1995, 565pp.

2. Sar E.; Ferrario M.E, Reguera B. Floraciones Nocivas en el Cono Sur Americano. Instituto Español de Oceanografía, Vigo, España, 2002, $311 \mathrm{pp}$.

3. Vargas-Montero M., Freer E. Descripción morfológica y ultraestructural de floraciones algales nocivas en el Golfo de Nicoya, Costa Rica y su impacto en la salud. Rev Cost de Ciencias Médicas. 2002 ; 23

4. John U., Quilliam M.A., Medlin L., Cembella A.. Spirolide production and photoperiod-dependent growth of the marine dinoflagellate Alexandrium ostendeldii. Proccedings of Harmful Algae Blooms, Ninth Conference Tasmania, Australia. 2000, 234pp.

5. Karnovsky M.J. A formaldehyde-glutaraldehyde fixative of high osmolarity for use in electrón microscopy. Jour. of Cell Biol. 1965; 27:137A.

6. Hargraves P., Víquez R. The dinoflagellates red tide in Golfo de Nicoya, Costa Rica. Rev. Biol. Trop. 1981; 29(1):31-38.

7. Hargraves P., Víquez R. Spatial and temporal distribution of phytoplankton in the Gulf of Nicoya, Costa Rica. Bull. Mar. Sci. 1985; 37:577-585.

8. Mata L., Abarca G., Marranghello L., Víquez R. Intoxicación paralítica por mariscos (IPM) por Spondylus calcifer contaminado con Pyrodinium bahamense, Costa Rica, 1989-1990. Rev. Biol.Trop.1990; 38 : 129-136.

9. Whyte J. N., Haigh N., Ginther G., Keddy J. First record of blooms of Cochlodinium sp. (Gymnodiniales, Dinophyceae) causing mortality to aquacultured salmon on the west coast of Canada. Phycologia, 2001; 40: 298-304.

10. Fukuyo Y, Takano H, Chihara M. et al. Red Tide Organisms in Japan. Uchida, Japan, 1990. pp.405.

11. Gusmán H.M., Cortés J., Glynn P.W., Richmond R.H.. Coral mortality associated with dinoflagellate blooms in the eastern Pacific (Costa Rica and Panamá). Mar. Ecol. Prog. Ser. 1990; 60:209-303.

12. Víquez R., Hargraves P.Annual cycle potentially harmful dinoflagellates in the Golfo de Nicoya, Costa Rica. Bull Marine Sci 1995; 57: 467475.

13. Vargas-Montero M., Freer E. First Report of Pyrodinium bahamense var. compressum and bahamense (Dynophyta: Peridinae) forming togheter a red tide at the Gulf of Nicoya, Costa Rica. Proccedings of the "4th International Conference on Molluscan Shellfish Safety", Santiago de Compostela, España, Junio 2002.

14. Morales A., Víquez R., Rodríguez K., Vargas M. Primer registro de una marea roja producida por Lingulodinium polyedrum (Gonyaulacales: Dinophyta) en Bahía Culebra, Golfo de Papagayo, Costa Rica. Rev. Biol.Tropl. 2001; Supl.49: 19-23.

15. Va rgas-Montero M., Freer E. Harmful Algae blooms of toxigenic diatom Pseudo-Nitzschia (Bacillariophyceae) in the Gulf of Nicoya, Costa Rica. Rev. Biol. Trop. 2002. En prensa Volumen especial Grupo ANCA.

16. Vargas-Montero M., Freer E. Floraciones Algales Nocivas de Cianobacterias (Oscillatoriaceae) y dinoflagelados (Gymnodiniaceae) en el Golfo de Nicoya, Costa Rica. Rev. Biol. Trop. 2002. En prensa.

17. Anderson D.M., Andersen P., Bricelj V.M., Cullen J.J., Rensel J.E. Monitoring and Management Strategies for Harmful Algal Blooms in Coastal Waters, APEC ·201-MR-01.1. Asia Pacific Economic Program, Singapore, and Interguvernamental Oceanographyc Commission Technical Series, Paris. 2001; No. 59,. 268 pp.

18. Cortés-Altamirano R. Las Mareas Rojas. A.G.T. Editor, S. A. México, D.F. 1998, 161pp.

19. Suárez B., Guzmán L. Mareas Rojas y Toxinas Marinas, Floraciones Algales Nocivas. Santiago de Chile, 1999, 77 pp.

20. Landsberg J. The Effects of Harmful Algae Blooms on Aquatic Organisms. En: Stickney R. Reviews in Fisheries Science. New York: Fisheries Science; 2002; 10:113-390. 
21. Herderson R., Ritchie J.M., Strichartz G.R. The binding of labelled saxitoxin to the Sodium Channel in nerve membranes. J. Physiol. 1973; 235:783-804.

22. Murata M, Kumagai JS, Lee JS et al. Isolation and structure of yessotoxin, a novel polyether compound implicated in diarrhetic shellfish poisoning. Tetrahedron. 1987;28:5869-5872.

23. Yasumoto T., Murata M., Oshima Y., Sano M., Matsumoto G.K., Clardy J. Diarrhetic Shellfish Toxins. Tetrahedron 1985; 41:1019-1025.

24. Yasumoto T., Murata M., Lee J.-S., Torigoe K... Polyether toxins produced by dinoflagellates. In Natori, S., K. Hashimoto \& Y. Ueno (eds), Mycotoxins and Phycotoxins. Elsevier,Amsterdam 1989; 375-382.

25. Cembella A.; Shumway S.E, Lewis N.I. Anatomical distribution and spatio-temporal variation of paralytic shellfish toxin composition in two bivalve species from the Gulf of Maine. Journal of Shellfish Research.1995; 12:389-403.

26. Bates S.S, Léger C., Satchwell M., Boyer G.L. The effects of iron on domoic acid production by Pseudo-Nitzschia multiseries. Proccedings of Harmful Algae Blooms, Ninth Conference Tasmania, Australia. 2000

27. Román Y., Alfonso A., Louzao C., de la Rosa L.A., Leira F., Vieites J.M., Vieites M., Ofuji K., Satake M., Yasumoto T., Botana L. Azaspiracid-1, a potent, monopoptotic new phycotoxin with several cell targets. Cellular Signallin 2002; 14: 1-14.

28. Cembella A., Bauder A., MacKinnon S., Quilliam M., Richard D., Walter J., Windust A. Spirolides:Emerging Phycotoxins in Plankton and Shellfish from the North Atlantic. Proccedings of the " $4^{\text {th }}$ International Conference on Molluscan Shellfish Safety", Santiago de Compostela, España, Junio 2002
29. Vargas-Montero M. Análisis ultraestructural de algunas especies de dinoflagelados marinos presentes en el Golfo de Nicoya, Costa Rica. Tesis. Universidad Nacional, Heredia, Costa Rica, 2001, 101pp.

30. James K.J, Furey A., Satake M., Yasumoto T.. Azaspiracid poisoning (AZP): a new shellfish toxic syndrome in Europe. Proccedings of Harmful Algae Blooms, Ninth Conference Tasmania, Australia. 2000

31. Andrew F., John D., Kane M.. Proccedings of Harmful Algae Blooms, Ninth Conference Tasmania 2000.

32. Vargas-Montero M., Freer E. Paralytic Shellfish Poisoning Outbreaks in Costa Rica. Proccedings of the " $\mathrm{X}^{\mathrm{th}}$ International Conference on Harmful Algae”, St. Pete Beach, Florida, Octubre 2002.

33. Ishida Y. I., Yoshinaga M.C., Kim, Uchima A. Possibility of bacterial control of harmful algal blooms. En M.T. Martins, M.I.Z. Sato, J.M. Tiedje, L.C.N. Hagler, J. Progress in Microbial Ecology. S.B.M/ICOME, Brazil, 1997, pp.495-500.

34. Doucette G.J., Kodama M., Franca S., Gallacher S.. Bacterial interactions with harmful algal bloom. Species bloom ecology, toxigenesis, and cytology. NATO ASI Series, Vol. G41. Physiological Ecology of Harmful Algal Blooms. 1998

35. Glibert P.M., Pitcher G. Global Ecology and Oceanography of harmful algal blooms. Science Plan. An International Programme sponsored by the Scientific Committee on Oceanic Research (SCOR) and the Intergovernmental Oceanographic Commission (UNESCO). 2001, 86 pp.

36. Valverde J. Floraciones algales en el Golfo de Nicoya, Costa Rica, Implicaciones en Salud Pública. Tesis UCR. 1999, 98 pp.

37. La Gaceta, 6 de marzo 2001.

\begin{tabular}{|c|c|c|c|c|c|}
\hline \multicolumn{6}{|c|}{$\begin{array}{c}\text { Cuadro } 1 \\
\text { Síndromes asociados a las floraciones algales nocivas en la costa pacífica de Costa Rica. }\end{array}$} \\
\hline Síndrome & $\begin{array}{l}\text { Toxinas } \\
\text { involucradas }\end{array}$ & Síntomas y signos & Método de detección & $\begin{array}{c}\text { Dinoflagelado } \\
\text { involucrado }\end{array}$ & Marisco portador \\
\hline Azaspirácidos & $\begin{array}{l}\text { Azaspirácidos y } \\
\text { sus análogos }\end{array}$ & $\begin{array}{l}\text { Náusea, vómito, diarrea } \\
\text { severa, calambres } \\
\text { estomacales similares a } \\
\text { los de la DSP }\end{array}$ & CL-EM * & $\begin{array}{l}\text { Protoperidinium spp. } \\
\text { P.crassipes }\end{array}$ & $\begin{array}{l}\text { Moluscos Mytilus } \\
\text { edulis y Crassostrea } \\
\text { gigas }\end{array}$ \\
\hline $\begin{array}{l}\text { Intoxicación } \\
\text { ciguatérica por } \\
\text { consumo de } \\
\text { peces }\end{array}$ & $\begin{array}{l}\text { Ciguatoxinas y } \\
\text { derivados }\end{array}$ & $\begin{array}{l}\text { desordenes } \\
\text { gastrointestinales, } \\
\text { cardiovasculares } \\
\text { y neurológicos }\end{array}$ & $\begin{array}{l}\mathrm{BR}^{\star *}, \mathrm{CL}-\mathrm{EM}^{*} \\
\mathrm{CLAP}-\mathrm{FD} / \mathrm{MS}^{* * *}, \mathrm{CLAP}^{* * * *}\end{array}$ & $\begin{array}{l}\text { Gambierdiscus tóxicos, } \\
\text { Prorocentrum sp. }\end{array}$ & peces de arrecife \\
\hline Espirolidos & espirólidos & & CL-EM ${ }^{*}$ & $\begin{array}{l}\text { Alexandrium ostenfeldii, } \\
\text { A.fundyense, } \\
\text { Prorocentrum lima. }\end{array}$ & ND \\
\hline $\begin{array}{l}\text { Intoxicación } \\
\text { diarréica por } \\
\text { consumo de } \\
\text { mariscos }\end{array}$ & $\begin{array}{l}\text { Acido okadaico y } \\
\text { análogos, } \\
\text { Pectenotoxinas, } \\
\text { Yesotoxinas }\end{array}$ & $\begin{array}{l}\text { Náusea, vómito, dolor } \\
\text { abdominal y diarrea }\end{array}$ & $\begin{array}{l}\text { BR }^{* *} \text {,bioensayo en rata } \\
\text { CLAP-FD** y CL-EM } \\
\text { ensayos in vitro de } \\
\text { inhibición de fosfatasas, } \\
\text { inmunoensayos e ELISA }\end{array}$ & $\begin{array}{l}\text { Dinophysis caudata, } \\
\text { Prorocentrum lima, } \\
\text { Gonyaulax grindleyi, } \\
\text { Lingulodinium polyedrum. }\end{array}$ & Moluscos bivalvos \\
\hline $\begin{array}{l}\text { Intoxicación } \\
\text { paralizante } \\
\text { por consumo } \\
\text { de mariscos }\end{array}$ & $\begin{array}{l}\text { Saxitoxinas y } \\
\text { derivados }\end{array}$ & $\begin{array}{l}\text { parestesia bucal, manos y } \\
\text { pies, cefalea, náuseas, } \\
\text { disartria, disnea }\end{array}$ & $\mathrm{BR}^{* *}, \mathrm{CLAP}-\mathrm{FD}^{* * *}$ & $\begin{array}{l}\text { Pyrodinium bahamense, } \\
\text { Gymnodinium catenatum }\end{array}$ & Moluscos bivalvos \\
\hline
\end{tabular}

